\title{
Narrativas dos profissionais da atenção primária sobre a política nacional de saúde integral da população negra
}

\author{
Primary care professionals' narratives about the national policy of black population \\ integral health
}

Josenaide Engracia dos Santos', Giovanna Cristina Siqueira Santos²

1 Mestre em Saúde Coletiva pela Universidade de Brasília (UnB) - Brasília (UnB), Brasil.

josenaidepsi@gmail.com

${ }^{2}$ Graduanda em Terapia Ocupacional pela Universidade de Brasília (UnB) - Brasília (UnB), Brasil.

giovanna_cristina@hotmail.com
RESUMO: O Conselho Nacional de Saúde aprovou, no dia 10 de novembro de 2006, a Política Nacional de Saúde Integral da População Negra (PNSIPN). Objetivo compreender os sentidos atribuídos pelos profissionais de saúde da atenção primária a respeito da PNSIPN. Metodologia. Construcionismo social, com entrevista semiestruturada. Análise por meio do mapa de associação de ideias. As narrativas dos profissionais trouxeram a tona que a política para população negra não deve representar responsabilidade social. É vista como desnecessária e promotora da discriminação. Observou-se que as temáticas apresentadas pelos profissionais da atenção primária estão relacionadas ao mito da democracia racial.

PALAVRAS-CHAVES: População Negra; Política de saúde; atenção primária a saúde.

ABSTRACT: The Brazilian National Health Council, on november 10th, 2006 approved the Policy of Integral Health of the Black Population. The objective of the research is perceive the meaning attributed by the care workers of primary care about the Policy of Integral Health of the Black Population. Methodology: Social Construccionism, with a semi-structured interview. The analysis was made through the map of association of ideas. The narratives of professionals brought up that the black population policy should not represent social responsibility and is taken as unnecessary and as discrimination's promoter. We observed that the issues showed by primary care professional are related to the racial democracy myth.

KEYWORDS: Black Population; Health Policy; Primary Health Care. 


\section{Introdução}

A Constituição Federal de 1988, no artigo 196, diz que "A saúde é direito de todos e dever do Estado" (BRASIL, 1988). Embora seja um avanço incontestável como direito do cidadão, não o é quando o Estado não assegura a todos a mesma qualidade de atenção à saúde, seja do ponto de vista regional ou étnico-racial.

A saúde da população negra tem sido objeto de políticas, pois possui características que conferem disparidades no que diz respeito às condiçóes de saúde, seja do ponto de vista individual ou coletivo. A fim de promover a equidade no que diz respeito à efetivação do direito humano à saúde dessa população, o Conselho Nacional de Saúde aprovou, no dia 10 de novembro de 2006, a Política Nacional de Saúde Integral da População Negra (PNSIPN). Instituída pela portaria no 992 , de 13 de maio de 2009 , tem como objetivo a promoção da equidade em saúde, em função de situações de risco, com vistas ao maior cuidado com a saúde da população negra. Lopes (2004) afirma que o cuidado se estabelece quando são consideradas as necessidades, o perfil socioeconômico, o gênero e a raça de uma população. A dificuldade em contemplar essa diversidade e pluralidade enfrentada pelos cuidadores pode comprometer a resolutividade de suas ações, principalmente na atenção primária à saúde.

A atenção primária à saúde, segundo Lago e Cruz (2001), é uma estratégia flexível caracterizada por meio do primeiro contato entre usuários e equipe de saúde, que garante uma atenção integral oportuna e sistemática em processo contínuo; está organizada em coordenação com a comunidade e concatenada com os demais níveis da rede sanitária para proteger, restaurar e reabilitar a saúde do indivíduo, família e comunidade, em um processo conjunto de produção social de saúde.

Produção social é entendida a partir da complexidade do sujeito que se relaciona ao desenvolvimento econômico, social, subjetivo, de gênero e étnico-racial. Um aspecto importante da atenção primária é a vinculação dos profissionais com a comunidade e com essas diversidades, o que é fundamental para a implementação de políticas públicas, com destaque às políticas de promoção de igualdade racial. Políticas de promoção de igualdade racial são compreendidas como políticas públicas que pretendem corrigir iniquidades decorrentes de discriminaçáo, histórica e atual, vivenciada pela população negra. Desse modo, a PNSIPN se caracteriza como uma política pública de promoção de igualdade racial em saúde que tem como objetivo atender às desigualdades que acometem a população negra, por meio de garantias de maior grau de equidade no que diz respeito à efetivação do direito humano à saúde, em seus aspectos de promoção, prevenção, atenção, tratamento e recuperação de doenças e agravos, dando ênfase àqueles de maior prevalência entre essa população.

No Brasil, a saúde da população negra, segundo Oliveira (2003), é um campo de estudos, pesquisas e assistência reconhecida do ponto de vista da legitimidade política, cujas bases científicas são inegáveis, ainda com pouca divulgação entre a população e os profissionais de saúde, para produzir sentido junto à sociedade. Esse sentido é aqui compreendido como um componente do contexto social construído e reproduzido que se articula, influenciando as açôes dos sujeitos, aspecto importante quando diz respeito aos profissionais que trabalham na atenção primária, na medida em que é necessário conhecer as barreiras que, eventualmente, possam existir no acesso e entendimento dessa política para atendimento de sujeitos que historicamente são tratados de maneira iníqua. Assim, o objetivo deste estudo é explicar e descrever os sentidos atribuídos pelos profissionais de saúde da atenção primária à PNSIPN. Desse modo, faz-se necessário compreender as narrativas dos profissionais da área e como se posicionam diante dessa política.

\section{Metodologia}

O presente estudo trata de uma pesquisa exploratória qualitativa. As pesquisas qualitativas são entendidas como aquelas capazes de incorporar a questão do significado e da intencionalidade como inerentes aos atos, às relações, e às estruturas sociais, sendo essas últimas tomadas como construções humanas significativas, tanto no seu advento quanto na sua transformação. Segundo Minayo (1993), o material primordial da investigação 
qualitativa é a palavra que expressa a fala cotidiana, seja nas relações afetivas e técnicas ou nos discursos intelectuais, burocráticos e políticos.

Optou-se, como teoria conceitual metodológica, pelo 'construcionismo' social. De acordo com Kenneth Gergen, (apud Spink, 2004. p.26):

\section{A investigação social-'construcionista’ preocu- pa-se com a explicação dos processos por meio dos quais as pessoas descrevem, explicam ou dão conta do mundo (incluindo a si mesmos) em que vivem.}

Essa abordagem possibilita capturar o processo da produção de sentidos nos contextos sociais. Spink (2010) define sentido como: 'uma construção social', um empreendimento coletivo, mais precisamente, interativo, por meio do qual as pessoas - na dinâmica das relaçóes sociais, historicamente datadas e culturalmente localizadas - constroem os termos a partir dos quais compreendem e lidam com situaçôes e fenômenos à sua volta.

A linguagem em ação focaliza as maneiras pelas quais as pessoas produzem sentidos e posicionam-se em relações sociais cotidianas. As práticas discursivas têm como elementos constitutivos a dinâmica, as formas e os conteúdos, e os repertórios linguísticos. Os repertórios linguísticos, para Spink (2004), são termos, conceitos, lugares comuns e figuras de linguagem que demarcam o rol de possibilidades de construções de sentidos. São repertórios que circulam na sociedade de formas variadas. O cenário da pesquisa foi o Centro de Saúde 8, cuja equipe é formada por profissionais da atençáo primária - médico, enfermeiro, odontólogo, assistente social, técnico de higiene dental e agente comunitário de saúde - que compóem a Estratégia de saúde da família (ESF) localizado em Ceilândia (DF). Os sujeitos da pesquisa foram dez profissionais da ESF, dos quais um médico, seis enfermeiros, uma assistente social e um agente comunitário de saúde.

No que diz respeito ao número de pessoas entrevistadas, Duarte (2002) afirma que o procedimento que se tem mostrado mais adequado é ir realizando entrevistas - a prática tem indicado um mínimo de 20 , variando em razão do objeto e do universo de investigação -, até que o material obtido permita uma análise mais ou menos densa das relaçôes estabelecidas naquele meio e a compreensão de "significados, sistemas simbólicos e de classificação, códigos, práticas, valores, atitudes, ideias e sentimentos" (DAUSTER, 1999, p.2). Os critérios de inclusão foram: indivíduos com idade superior a 18 anos de ambos os sexos, com vínculo empregatício de mais de um ano e que aceitassem participar voluntariamente da pesquisa.

A coleta de dados constituiu-se de uma entrevista semiestruturada. Pinheiro (2004) considera a entrevista como "prática discursiva, ou seja, entendê-la como ação - intenção - situada e contextualizada, por meio da qual se produzem sentidos e se constroem versóes da realidade." A entrevista materializa através da linguagem a experiência do indivíduo. O termo experiência é utilizado historicamente por Heidegger e explicado por Minayo (2012, p.622): "O sentido da experiência é a compreensão: o ser humano compreende a si mesmo e ao seu significado no mundo da vida". Por ser constitutiva da existência humana, a experiência alimenta a reflexão e se expressa na linguagem.

A análise dos dados foi realizada por meio do Mapa de Associação de Ideias que, de acordo com Spink (2010, p.38),

são instrumentos de visualização do processo de interanimação que possibilitam, entre outras coisas, mostrar o que acontece quando perguntamos certas coisas ou fazemos certos comentários.

O Mapa nada mais é que uma tabela onde as colunas são definidas tematicamente e os temas refletem as três perguntas norteadoras da entrevista. Conforme Spink e Lima (2004), esse é um recurso para produzir sentido e compreender determinadas passagens das entrevistas.

As normas e diretrizes do Conselho Nacional de Saúde, Resolução no 466 de 12 de dezembro de 2012, que regulamentam a pesquisa envolvendo seres humanos, foram obedecidas e atendidas. A pesquisa foi autorizada pelo Comitê de Ética em Pesquisa da Fundação 
de Ensino e Pesquisa em Ciências da Saúde - FEPECS, de número 239.796/2013.

\section{Resultados}

Neste estudo, foi possível conhecer os sentidos atribuídos pelos profissionais à PNSIPN a partir de suas narrativas. Para Ricoeur (1997), a narrativa seria uma operação mediadora entre a experiência viva e o discurso que se abre à interpretação, ao mesmo tempo em que estabelece condiçôes para sua circulação, recepção e produção que se articula, consoante Lyotard (2006), com as relações de poder, políticas, identitárias, contextuais, percebidas tanto diacrônica quanto sincronicamente, o que denota a relação das narrativas com os discursos sociais, aspectos importantes para entendimento dos sentidos que os profissionais de saúde atribuem à PNSIPN. $\mathrm{Na}$ análise, identificaram-se os atributos relacionados à explicação da política:

\section{Náo exigência social: a política para população ne- gra náo deve representar responsabilidade social.}

Os relatos mostram que não deve existir responsabilidade social com a PNSIPN, na medida em que a população negra não apresenta desigualdades que impliquem política especial. O que pode se perceber dos repertórios é que não aceitam a iniquidade racial, como se vê abaixo:

A gente sabe que o idoso tem que ter um atendimento especifico, né? Agora pro negro não, porque pra mim branco e negro são iguais, né? Não tem essa diferenciação em relação à saúde. (E2)

Mas para a população negra, por quê? Porque são melhores? Porque são piores? Porque se hoje brigam tanto por igualdade porque vai fazer esse, trazer esse abismo de novo? (E3)

Para Trad e Brasil (2012), a PNSIPN é justificada por meio da necessidade de se repensar a igualdade de açóes e serviços, adotando a lógica de que a igualdade não pode ser justa: este é o primeiro passo para tal aceitação da iniquidade racial como fenômeno amplo que precisa ser combatido em todas as esferas.

\section{Acho que não tem necessidade disso, não. Prio-} rizar, não. (E4)

Os discursos revelam que as políticas de promoção da igualdade racial ferem o princípio constitucional da igualdade e que as políticas universalistas contemplam a todos igualitariamente, não ponderando que tais políticas não levam em conta a posição relativa de cada sujeito ou grupo dentro da sociedade, não atendendo, desse modo, ao princípio de igualdade.

Então acho que não cabe sentido, até que tá todo mundo brigando por direitos iguais, tem direito na universidade, direito disso, direito daquilo. Quer ficar junto com todo mundo, não 'todo mundo é igual perante a lei', porque você vai discriminar na área da saúde? (E3)

Náo tinha que ter que brigar por uma causa. Porque é negro, porque tem mais dificuldade então vamos conseguir essa imposição para alcançar aquele objetivo. Acho que deveria ser no geral. A saúde não é para todos?' (E5)

As narrativas explicam que não há sentido em uma política específica, pois todos são iguais. Esse reconhecimento privilegia, antes de tudo, a figura de um indivíduo abstrato que se tornou o denominador comum universal. Retrata, também, uma dificuldade de compreensão, como afirma Arendt (2007), de que os homens não nascem iguais e não são iguais. As falas revelam que a exigência da igualdade, quando se vale da ideia de cidadão na sua formulação contemplativa, pode incorrer em acomodação de importantes disparidades em termos de raça, sexo, entre outros fatores. Este entendimento nos remete, ainda, a Malta (2001), que sinaliza que as desigualdades entre as pessoas não são dadas naturalmente, mas construídas pelo processo 
histórico e pelo modo de produção e organização da sociedade.

\section{Racismo ao contrário: a política para populaçáo negra deriva de uma discriminaçáo}

Os repertórios aparecem repletos de conteúdos que veem a politica para população negra como fruto da discriminação e do racismo, e náo da necessidade historicamente deteminada de saúde social. Nascimento (1994) denomina esse fenômeno como uma forma contundente de intolerância social.

Agora me deu uma lembrança do 'Apartheid' (risos). Por quê, né? Essa diferenciação. (E2)

Porque isso aí seria uma discriminação. Até com quem não iria ser favorecido com aquilo, se todo mundo é tratado igual, se todo mundo tem as mesmas condiçôes de atendimento, precária, mas tem. (E3)

Quer ficar junto com todo mundo, não 'todo mundo é igual perante a lei, porque você vai discriminar na área da saúde? (E4)

Nesse contexto dos relatos, é importante refletir sobre as políticas públicas voltadas ao desafio da redução das desigualdades raciais que não são consideradas nas narrativas, pois, para os entrevistados, a PNSIPN provoca uma nova desigualdade, ou seja, existe nos discursos espaço privilegiado dos negros ao se confirmar a política específica. Cunha (2012) credita essa resistência à crença de racismo na sociedade brasileira à opiniáo de que, no Brasil, se vive uma 'democracia racial' e que, ao enfocar esse recorte analítico, fomentar-se-ia um racismo inexistente. É bom ressaltar que racismo, segundo Lopes (2004), é uma programação social e ideológica às quais todos estão submetidos; não é questão de opinião. Uma vez envolvidas nessa programação social, as pessoas reproduzem, consciente ou inconscientemente, atitudes racistas que, em certos casos, são inteiramente opostas à sua opiniáo.

\section{Atendimento prioritário como privilégio}

A PNSIPN é descrita como concessão de privilégio que favorece a um grupo em especial. De certa forma, silenciam-se as evidências empíricas da exclusão do negro em todas as áreas e reafirmam-se as práticas discriminatórias que perpassam o cotidiano dos profissionais legitimadas pelo discurso abaixo:

O negro é quem vai ter prioridade pra pegar a medicação. (E2)

De informar que eles têm um risco maior de ter essas doenças, esses problemas, anemia, doenças crônicas, hipertensão, diabetes, mas sinceramente... (E2)

Nas narrativas, é possível perceber o mito da democracia racial, ou seja, de que não existe racismo no Brasíl e, portanto, uma política específica seria privilégio. Ao entrar no mérito de critérios raciais na área da saúde, a máxima biológica de que não existem raças, principalmente em nosso país, onde a miscigenação teria fundado, segundo Bernardino (2002), uma essência biológica única, é usada, muitas vezes, como escudo para qualquer tentativa de se refletir sobre políticas que tentam corrigir iniquidades raciais. Ainda segundo o autor, essa recusa em se reconhecerem raças seria estratégica e ocorreria somente em momentos onde se discutem concessões de eventuais benefícios àqueles que são identificados como grupo de menos status.

\section{Política como privaçáo de direitos}

A política é descrita como um instrumento de privação do direito constitucional à igualdade. $\mathrm{E}$ as políticas compensatórias para a população negra implicariam a redução dos direitos constitucionais da parcela da população que não é alvo dessas políticas. Segundo Rocha e Göttems (2009), nas políticas de promoção de igualdade racial, a igualdade formal em que todos são iguais perante a lei sede lugar à igualdade material e seu ideal de justiça social e distributiva, adotanto, para reconhecimento dessa igualdade, o critério racial ou outros mais. 
Se você colocar uma politica 'anemia falciforme, vamos designar esse tratamento só pra população negra', e se o cara chegar lá morrendo de anemia e for um branco? Voce não vai ser assistido? (E3)

Mas, assim, você acha que a cor da pele vai influenciar em alguma coisa? O que diferencia meu estado de saúde, porque eu sou mais clara, do outro que é negro? Nós temos a mesma idade, estamos com o mesmo problema de saúde, ai porque ela é negra ela vai receber, vai ser imposto que ela vai receber o atendimento e o outro, só porque ele é de pele clara, ele vai ter que ficar de fora... Assim, vai ter que correr atrás do direito que ele... Entendeu? (E5)

As falas evidenciam que ações que visam à igualdade racial não são justificáveis, ou seja, que não existem desigualdades raciais que fundamentem um tratamento diferenciado para a população negra.

Ai tem a politica só pra negro, só pra branco, 'ah não, vou contratar um médico só pra negro, num pode ser um branco, tem que ser um negro', e a enfermeira 'não, tem que ser uma negra, a branca vai me atender? (E3)

Se diferenciar um atendimento específico a certa população, ai é que o trem não funciona mesmo. Pra todo mundo já não tá funcionando, se você adequar isso pra uma parte da população e outra política só pra outra parte, acho que ai é que vai travar o sistema, que não vai funcionar mesmo. (E3)

O descaso com relação à necessidade de investimento na saúde da população negra tem sido uma das faces mais perversas do racismo, pois, segundo Figueroa (2004), nega a possibilidade de promover e manter condições dignas de saúde a esse grupo, perpetuando a presença da população negra nos piores índices nacionais em termos de preservação da saúde.
Contrariamente ao que as falas evidenciam, as políticas de promoção da igualdade racial não significam um deslocamento das açóes universais como estratégia central da intervenção na vida social. Segundo Jaccoud (2008), é preciso reconhecer seu papel como instrumento de melhorias nas condiçóes de vida da população brasileira, inclusive da população negra. Mas é necessário notar que os fatores históricos e os contrangimentos raciais que ainda imperam no país impedem que as políticas universais sejam suficientes ao objetivo de enfrentar a discriminação e a desigualdade racial.

\section{Discussão}

Para registrar, ou melhor, colocar 'o preto no branco', as explicaçóes da PNSIPN contidas nos discursos dos profissionais da atenção primária são endereçadas ao mito da democracia racial, que perpassa todas as narrativas. Essa compreensão acerca do tema remete, também, à discriminação racial como um complexo sistema velado de programação social, presente em todas as maneiras em que as pessoas - conscientemente ou não -, por meio de suas práticas discursivas, produzem realidades sociais e psicológicas (DAVIES; HARRÉ, 1900, p.43). Ficou evidente que o profissional tende a náo perceber a discriminação ou a insistir em sua inexistência, contribuindo, assim, para a inação do sistema frente à discriminação e, consequentemente, para sua manutenção e ampliação.

Segundo Veloso (2006), uma sociedade que discrimina e nega a discriminação procura deixar claro que as políticas de igualdade racial são um equívoco e não um mecanismo reparador da igualdade. Assim, a questão é vista como desnecessária e promotora da discriminação. Ruas apud Xavier (2012), entende que, para se compreender o fenômeno saúde-doença em uma abordagem social e epidemiológica, é necessário considerar a referência racial e étnica como elemento básico determinante das desigualdades e iniquidades no acesso à saúde. A atenção primária deve se caracterizar por um atendimento que considere o sujeito em sua singularidade, complexidade, integralidade e inserção 
sociocultural, o que náo foi contemplado no discurso dos profissionais.

\section{Considerações}

temos o direito a ser iguais quando a nossa diferença nos inferioriza; e temos o direito a ser diferentes quando a nossa igualdade nos descaracteriza. Dai a necessidade de uma igualdade que reconheça as diferenças e de uma diferença que não produza, alimente ou reproduza as desigualdades (SANTOS, 2003, p.56).

Nesta pesquisa, observou-se que as temáticas para explicar e descrever o sentido da PNSIPN atribuídas pelos profissionais da atenção primária são as mesmas que circulam e são compartilhadas pelos que vivem e interagem no dia a dia. Tal discurso é repetidamente reforçado e cristalizado pela mídia, pelo universo empírico, acadêmico, e reproduzido por pessoas como um caleidoscópio de açóes e interaçóes que as situam no mundo. Ao refletir acerca da temática abordada, percebe-se que o sentido majoritário atribuído à PNSIPN é, em um primeiro momento, corroborado pelo mito da democracia racial discriminatória que busca dar sentido àquilo que não faz sentido, pois não contempla a realidade e a lógica. De certa forma, é um coro de profissionais que entoam as dissonâncias e fazem emergir falsa igualdade de uma população desigual. Não se pode esquecer que, segundo Almeida (2007), somente tratando diferentemente os desiguais, segundo a própria 'regra da justiça', poder-se-á alcançar uma maior igualdade entre os grupos.

\section{Referências}

ALMEIDA, M.M.M. Seminário Nacional Movimentos Sociais, 2, Participação e Democracia 25 a 27 de abril de 2007, UFSC, Florianópolis. Anais. Cidade, Núcleo de Pesquisa em Movimentos Sociais - NPMS

ARENDT, H. A Condição humana. Rio de Janeiro: Editora Forense universitária, 2007.

BERNARDINO, J. Ação Afirmativa e a Rediscussão do Mito da Democracia Racial no Brasil. Estudos Afro-Asiáticos, ano 24, n.2, p.247273,2002

BRASIL. Ministério da Saúde. Política Nacional de Saúde Integral da População Negra. Brasília, 2007.

Presidência da República. Constituição da República Federativa do Brasil de 1988. Artigo 196.

CONSELHO NACIONAL DE SÁUDE. Diretrizes e Normas Regulamentadores de Pesquisa Envolvendo Seres Humanos. Disponível em: <http://conselho.saude.gov.br/resolucoes/2012/Reso466.pdf> Acesso em: 9 dez 2013.

CUNHA, E.M.G.P. Recorte étnico-racial: caminhos trilhados e novos desafios. In: BATISTA, L.E. et al. Saúde da População Negra. Brasília: ABPN, 2012. p.37-48.
DAVIES, B.; HARRÉ, R. Positioning: The discursive production of selves. Journal for the theory of social behavior, v. 20, p. 43-65, 1990.

DAUSTER, T. A fabricação de livros infanto-juvenis e os usos escolares: o olhar de editores. Revista Educação, Rio de Janeiro, n.49, p.1-18, nov., 1999

DUARTE, R. Pesquisa qualitativa: reflexões Sobre o trabalho de campo. Cadernos de Pesquisa, n.115, mar., 2002.

FIGUEROA, A. Saúde da População Negra no Brasil: contribuições para a promoção da equidade. Brasília: FUNASA/MS; UNESCO, 2004.

JACCOUD, L. O combate ao racismo e à desigualdade: o desafio das políticas públicas de promoção da igualdade racial. In: THEODORO, M. (Org.) As políticas públicas e a desigualdade racial no Brasil 120 anos após a abolição. 2. ed. Brasília: IPEA, 2008.

LAGO, E.R.L.; CRUZ, R.R. Atención Primaria de Salud y medicina general integral. In: SINTES, R.A. Temas de medicina general integral. La Habana: Ciências médicas, 2001. p.07-28.

LOPES, F.; Experiências desiguais ao nascer, viver, adoecer e morrer: tópicos em saúde da população negra no Brasil. Caderno de Textos Básicos do I Seminário Nacional de Saúde da População Negra, de 18 a 20 de agosto de 2004, Brasília, 2004. 
LYOTARD, J. F. A condição pós-moderna. 9. ed. Rio de Janeiro: José Olympio, 2006.

MALTA, D.C Buscando novas modelagens em saúde: as contribuições do projeto vida e o acolhimento na mudança do processo de trabalho na rede pública de Belo Horizonte, 1993-1996. Tese (Doutorado em Saúde Coletiva) - Unicamp, Campinas, 2001.

MINAYO, M.C.S. O desafio do conhecimento: pesquisa qualitativa em saúde. 8. ed. São Paulo: Hucitec, 2004.

MINAYO, M.C.S.; SANCHES, O. Quantitativo-qualitativo: Oposição ou Complementariedade? Caderno de Saúde Pública, Rio de Janeiro, v.9, n.3, p.239-262, jul./set., 1993.

MINAYO, M.C.S. Análise qualitativa: teoria, passos e fidedignidade. Ciências \& Saúde Coletiva, Rio de Janeiro, v.17, n.3, mar., 2012.

NASCIMENTO, E. Hipóteses sobre a Nova Exclusão Social. Cadernos CHR, Salvador, n.21, 1994.

OLIVEIRA, F. Saúde da população negra. Brasília, Organização Pan-Americana da Saúde, 2003. p.195.

PINHEIRO, O.G. Entrevista: uma prática discursiva. In. SPINK, M.J. (Org.). Práticas discursivas e produção de sentidos no cotidiano: aproximação teórica e metodológica. 3.ed. São Paulo: Cortez, 2004.

RICOEUR, P. Tempo e narrativa. Campinas: Papirus, 1997. v.1.

ROCHA, T.B.; GÖTTEMS, C.J. A política de cotas nas universidades: em busca da efetividade do direito a educação. Congresso Nacional do CONPEDI, 18, São Paulo, 04 a 07 de novembro de 2009, Anais. São Paulo, 2009.
SANTOS, B.S. Reconhecer para libertar: os caminhos do cosmopolitanismo multicultural. Rio de Janeiro: Civilização Brasileira, 2003.

SPINK, M.J. Linguagem e produção de sentidos no cotidiano. Centro Edelstein de Pesquisas Sociais, Rio de Janeiro, 2010.

SPINK, M.J.; LIMA, H. Rigor e visibilidade: a explicitação dos passos da interpretação. In: SPINK, M.J. (Org.). Práticas discursivas e produção de sentidos no cotidiano: aproximações teóricas e metodológicas. 2. ed. São Paulo: Cortez, 2004, p.93-122.

TRAD, L.A.B.; BRASIL, S.A. O movimento negro na construção da Política Nacional de Saúde Integral da População Negra e sua relação com o estado brasileiro. In: BATISTA, L.E. et al. Saúde da População Negra. Brasília: ABPN, 2012. p.70-97.

VELOSO, G.M. Cotas na universidade pública: direito ou privilégio? UniMontes Científica, Montes Claros, v.8, n.2, jul./dez., 2006.

XAVIER, E.C. O olhar das mulheres quilombolas sobre a atenção básica e das profissionais das unidades básicas sobre a saúde das comunidades remanescentes de quilombos urbanas de Porto Alegre. In: BATISTA, L.E. et al. Saúde da População Negra. Brasília: ABPN, 2012. p.193-208.

Recebido para publicação em dezembro de 2013

Versão final em dezembro de 2013

Conflito de interesse: não houve

Suporte financeiro: inexistente 